\title{
Per Deciliter
}

National Cancer Institute

\section{Source}

National Cancer Institute. Per Deciliter. NCI Thesaurus. Code C105514.

A volume unit equal to one deciliter used as a denominator to build a derived unit expressed as a ratio. 